WAGNER, Patrick, Bauern, Junker und Beamte. Lokale Herrschaft und Partizipation im Ostelbien des 19. Jahrhunderts

\title{
Thierry Jacob
}

\section{(2) OpenEdition \\ Journals}

Édition électronique

URL : http://journals.openedition.org/ifha/1872

DOI : 10.4000/ifha.1872

ISSN : 2198-8943

Éditeur

IFRA - Institut franco-allemand (sciences historiques et sociales)

Référence électronique

Thierry Jacob, «WAGNER, Patrick, Bauern, Junker und Beamte. Lokale Herrschaft und Partizipation im Ostelbien des 19. Jahrhunderts », Revue de l'IFHA [En ligne], Date de recension, mis en ligne le 01 janvier 2009, consulté le 22 septembre 2020. URL : http://journals.openedition.org/ifha/1872 ; DOI : https:// doi.org/10.4000/ifha.1872

Ce document a été généré automatiquement le 22 septembre 2020.

(C)IFHA 


\title{
WAGNER, Patrick, Bauern, Junker und Beamte. Lokale Herrschaft und Partizipation im Ostelbien des 19. Jahrhunderts
}

\author{
Thierry Jacob
}

1 Issu d'une habilitation soutenue à l'Université de Fribourg en 2003, cet ouvrage invite à une profonde relecture des rapports de force et des structures et pratiques d'exercice du pouvoir local au sein des sociétés rurales de l'Est prussien entre 1830 et 1910 . Pour ce faire, l'auteur adopte une démarche résolument dynamique là où l'historiographie $\mathrm{a}$ au contraire longtemps favorisé une approche faisant la part belle aux facteurs de continuités et d'immobilisme.

2 P.W. remet en effet en cause deux idées forces : d'une part, celle de la domination politique sans partage des gros propriétaires fonciers nobles, la fameuse Junkerherrschaft, sur les campagnes prussiennes, d'autre part le fait que ces dernières seraient restées à l'écart des transformations politiques du XIXe s. Partant du constat que ces acceptions reposent sur une faible couverture empirique et sur les jugements de contemporains, Max Weber en tête, l'auteur fonde sa recherche sur un intense travail d'archives (à l'exemple des provinces de Prusse orientale et occidentale et du Regierungsbezirk Breslau, en Silésie) et sur la définition d'une vaste palette de questionnements réunis en deux interrogations principales : premièrement, une analyse des rapports de force au sein des campagnes en fonction d'une dialectique continuité/transformation et deuxièmement, une étude des étapes de la pénétration de l'État au sein des campagnes (Durchstaatlichung) et du degré selon lequel il a cherché à remodeler les structures du pouvoir local au détriment des élites traditionnelles.

3 L'angle d'attaque choisi est la prise en compte de la loi de réforme de l'administration locale de 1872 (Kreisordnungsgesetz) qui a profondément transformé l'ordre politique des campagnes, mais à laquelle l'historiographie n'a pas rendu toute son importance. Cette loi, qui a réformé les modes d'élection et de gouvernance des Kreistage et le mode 
de nomination comme la fonction du Landrat, a non seulement mis (partiellement) fin aux structures patriarcales de pouvoir mais a surtout fait émerger deux nouveaux acteurs : la paysannerie et l'administration. Toute l'originalité de l'ouvrage, comme le souligne son titre, est alors de ne pas enfermer la question du pouvoir local dans la confrontation entre les Junker et les Landarbeiter mais, au contraire, de le restituer au sein du «triangle " que forment les gros propriétaires, nobles comme bourgeois, la paysannerie et l'administration (ainsi que d'autres acteurs, le pasteur restant cependant absent).

Difficile ici de rendre compte du foisonnement et de la richesse des apports d'un ouvrage densément écrit. L'étude se divise en trois parties, de part et d'autre de la loi de 1872. La première décrit l'érosion des structures patriarcales traditionnelles et les avancées de l'État au sein des campagnes dans les deux premiers tiers du XIXe s. Cœur de l'étude, la seconde partie restitue la genèse, les dispositions de la loi de 1872, ainsi que les nouveaux acteurs politiques locaux qu'elle met en place, tandis que la dernière partie, plus dynamique, en mesure les implications institutionnelles et les transformations qu'elle a générées en termes de rapports de force entre les élites traditionnelles et les représentants de l'État. Une figure-clef des campagnes prussiennes, le Landrat, fait l'objet de toute l'attention de P.W., qui montre combien ce dernier n'est désormais plus le représentant de la grosse propriété foncière mais celui du pouvoir central, et qu'il agit comme un "Broker », un intermédiaire, entre la sphère étatique et les divers acteurs sociaux, notamment en prenant en charge la défense du conservatisme politique mais aussi celle des intérêts agricoles et ruraux.

5 Deux conclusions, majeures, se dégagent de cet ouvrage. D'une part, les campagnes prussiennes n'étaient en rien au plan politique un monde immobile, mais au contraire un monde en pleine transformation, riche en conflits, où le statut d'élite locale ne reposait plus sur le caractère corporatiste, mais sur la qualification, l'élection et l'acquisition de mérites individuels. D'autre part, l'État et ses représentants sont devenus un acteur politique central, au pouvoir sans cesse progressant, déterminant les hiérarchies et les conditions de participation au pouvoir local. Pour l'auteur, en 1900, les Junker ne seraient ainsi plus une Herrschaftsklasse, mais une élite locale tirant son pouvoir de la protection que lui octroie la bureaucratie.

Thierry JACOB (Université Lumière-Lyon II) 